\title{
Public health nutrition workforce development in seven European countries: constraining and enabling factors
}

\author{
Susanna Kugelberg ${ }^{1,2, *}$, Svandis Jonsdottir ${ }^{3}$, Elisabeth Faxelid ${ }^{4}$, Kristina Jönsson ${ }^{5}$, \\ Ann Fox ${ }^{6}$, Inga Thorsdottir ${ }^{3}$ and Agneta Yngve ${ }^{1,2}$ \\ 'Unit for Public Health Nutrition, Karolinska Institutet, Hälsovägen 7, 14157 Huddinge, Stockholm, Sweden: \\ ${ }^{2}$ Department of Health, Nutrition and Management, Oslo and Akershus University College of Applied Sciences, \\ Oslo, Norway: ${ }^{3}$ Unit for Nutrition Research, University of Iceland and Landspitali National University Hospital, \\ Reykjavik, Iceland: ${ }^{4}$ Division of Global Health/IHCAR, Department of Public Health Sciences, Karolinska Institutet, \\ Stockholm, Sweden: ${ }^{5}$ Department of Political Science, Lund University, Lund, Sweden: ${ }^{6}$ Department of Nutritional \\ Sciences and The Dalla Lana School of Public Health, University of Toronto, Toronto, Ontario, Canada
}

Submitted 2 February 2012: Final revision received 5 July 2012: Accepted 5 July 2012: First published online 16 August 2012

\begin{abstract}
Objectives: Little is known about current public health nutrition workforce development in Europe. The present study aimed to understand constraining and enabling factors to workforce development in seven European countries.

Design: A qualitative study comprised of semi-structured face-to-face interviews was conducted and content analysis was used to analyse the transcribed interview data. Setting: The study was carried out in Finland, Iceland, Ireland, Slovenia, Spain, Sweden and the UK.

Subjects: Sixty key informants participated in the study.

Results: There are constraining and enabling factors for public health nutrition workforce development. The main constraining factors relate to the lack of a supportive policy environment, fragmented organizational structures and a workforce that is not cohesive enough to implement public health nutrition strategic initiatives. Enabling factors were identified as the presence of skilled and dedicated individuals who assume roles as leaders and change agents.

Conclusions: There is a need to strengthen coordination between policy and implementation of programmes which may operate across the national to local spectrum. Public health organizations are advised to further define aims and objectives relevant to public health nutrition. Leaders and agents of change will play important roles in fostering intersectorial partnerships, advocating for policy change, establishing professional competencies and developing education and training programmes.
\end{abstract}

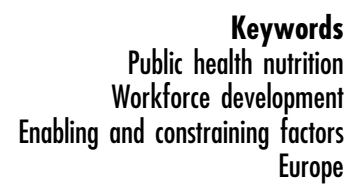

Governments recognize that the burden of disease attributable to nutrition is substantial and that the evidence concerning the role of diet and nutrition in the development of disease and health-related conditions, such as diabetes ${ }^{(1)}$ and obesity ${ }^{(2)}$, is significant. Policies and national action plans related to nutrition have gained increasing political recognition in the European region since $2000^{(3)}$.

The recognition of workforce development, as part of developing a nation's capacity to address public health issues, has been growing ${ }^{(4,5)}$. The relationship between the organization of public health nutrition services and the nutrition-related well-being of populations is a key focus of public health nutrition practice, and is reflected in the definition of public health nutrition established at the 1st World Congress of Public Health Nutrition held in Barcelona in 2006. 'Public health nutrition' is defined as 'the promotion and maintenance of nutrition-related health and wellbeing of populations through organized efforts and informed choices of society, ${ }^{\text {(6) }}$.

The discipline of public health nutrition is emerging worldwide $^{(7,8)}$. The literature on public health nutrition workforce development in Europe has focused on training and the need for development of competencies, with no studies explicitly exploring the broader socio-political conditions that affect the workforce ${ }^{(9-14)}$. Hughes claims it is a mistake to equate workforce development with training initiatives and recommends research strategies that can inform policy development and capacity development ${ }^{(4)}$. Public health nutrition advocates suggest that we need to know more about the policy environment that shapes workforce demand, infrastructure and composition in order to take appropriate action to prevent nutritionrelated disease ${ }^{(15,16)}$. 
Qualitative research strategies can provide insights into the constraining and enabling factors associated with workforce expansion, programme implementation and capacity development, all of which can inform policy making. This kind of information is vital to research development and to inform policy making. In the present paper we apply a qualitative approach to understand workforce development in Finland, Iceland, Ireland, Slovenia, Spain, Sweden and the UK. The diversity of countries included in the study is intended to provide insight into a wide range of factors that affect workforce development. While the scope of the paper does not permit in-depth analysis of the workforce in each of these countries, we acknowledge that the public health nutrition workforce in each reflects unique historical, political, social and economic contexts which are worthy of further study.

\section{Workforce development}

Workforce development is a concept which includes strategies for workforce planning, capacity building and management of workforce resources ${ }^{(4,17-20)}$. The definition of public health workforce development provided by Staron ${ }^{(20)}$ embraces the above approach: "Workforce development is a holistic concept that integrates workforce analysis and planning, human resource management and capability development to strengthen organisation success by aligning the workforce to both current and future service demands.'

At a structural level, workforce development aims to improve the functioning of the entire workforce by focusing on systems and structures that shape it, i.e. supportive, policies, resource allocation, regulations, etc. At an individual level, workforce development focuses on the organizational climate and access to knowledge and skills development, on-the-job learning, mentoring, etc. On a third level, it involves strategies for workforce preparation, i.e. to create the future generation of the workers by promoting recruitment, enhancing access to education and ensuring quality training.

This definition positions the organization of public health services as a fundamental aspect of workforce development. In Europe, workforce demand is shaped partly at national level, where creation of country-specific interventions leads directly to workforce delivery of programmes. It is therefore important to consider how the policy environment shapes the workforce. The literature therefore highlights the importance of alignment of public health nutrition objectives at the national level with service delivery at more local and regional levels of implementation. There is a wide range of organizations that contribute to the public health nutrition infrastructure providing these services, including government (e.g. national, local, regional health services, public health agencies, food safety agencies); universities and other training institutions; non-governmental organizations/community organizations; and the private sector (e.g. private research companies, food industry).

In addition, literature suggests that public health nutrition is a multidisciplinary field with no clear professional boundaries ${ }^{(21-24)}$ for delivering programmes and services that promote health and well-being among populations $^{(25)}$.

The desired outcome of public health workforce development is the improvement of the nutrition-related health of populations. In order for this to happen, there needs to be: (i) support for public health nutrition development at the policy-making level; (ii) service delivery at the organizational level; and (iii) competence and capacity within the workforce itself. We therefore aimed to examine constraining and enabling factors related to the policy environment, to public health organizations and to workforce composition in seven countries within the European Union.

Throughout the remainder of the paper, public health nutrition is referred to as PHN.

\section{Methods}

Qualitative approaches are often used when there is little known about the phenomena under investigation. In social and policy research, qualitative methods have been used to understand complex behaviours, needs and systems ${ }^{(26)}$. Qualitative analysis can highlight important aspects of policy, reveal underdeveloped policy areas, suggest improved structures for policy implementation and inform future strategies ${ }^{(27)}$. The gaps in current research regarding workforce development of public health nutritionists in Europe, and our aim to understand workforce development across countries, necessitated such an approach.

\section{Data collection}

Data were collected through individual face-to-face interviews for all but one interview, which was conducted by telephone due to an unforeseen complication. An interview guide was developed to facilitate discussion on a number of key issues relevant to PHN workforce development and was informed by the workforce development literature. The guide covered contextual issues (training background, wider policy context and current work); issues related to workforce development; and needed roles and competencies of public health nutritionists. A sample of questions on the interview guide is shown in Table 1. The first author, who has a double degree in political science and PHN, conducted all interviews. English was used during the interviews, with the exception of those in Sweden, where interviews were conducted in Swedish. Interviews were audio-recorded, lasted 30-60 min and were transcribed verbatim. 
Table 1 Sample of interview questions

\begin{tabular}{|c|c|c|}
\hline Key theme & Focus & Example interview question \\
\hline \multirow[t]{3}{*}{ Policy context } & Negotiation and decision-making structure & $\begin{array}{l}\text { Who are the leading actors in the process of formulating } \\
\text { PHN polices? }\end{array}$ \\
\hline & Problem definition and agenda setting & $\begin{array}{l}\text { Today, how does the government rank PHN as an } \\
\text { important area for action? (probe: Within public health?) }\end{array}$ \\
\hline & Workforce considered and rationale & $\begin{array}{l}\text { What professionals are favoured by the government to } \\
\text { implement PHN policies? Why? }\end{array}$ \\
\hline \multirow[t]{3}{*}{ PHN infrastructure } & Infrastructure & $\begin{array}{l}\text { How would you describe the structure and main } \\
\text { organizations in your country to deliver PHN services? }\end{array}$ \\
\hline & Planned and current initiatives & $\begin{array}{l}\text { What initiatives are planned or being implemented in your } \\
\text { region to address PHN issues? }\end{array}$ \\
\hline & Leaderships & $\begin{array}{l}\text { If you think about colleagues who you would consider as } \\
\text { PHN exemplars, what attributes and skills do they have } \\
\text { that contribute to their status? }\end{array}$ \\
\hline \multirow[t]{3}{*}{ Workforce composition } & Professions considered & $\begin{array}{l}\text { How would you describe the composition/structure of the } \\
\text { national-wide PHN workforce (i.e. those who make } \\
\text { contributions to PHN efforts)? Who? }\end{array}$ \\
\hline & Workforce development roles/functions & $\begin{array}{l}\text { What would you consider being the core functions of the } \\
\text { PHN workforce? }\end{array}$ \\
\hline & Competencies & $\begin{array}{l}\text { What competencies (skills, knowledge and attitudes) } \\
\text { would you identify as being necessary for effective } \\
\text { PHN practice? }\end{array}$ \\
\hline
\end{tabular}

PHN, public health nutrition.

\section{Choice of informants}

Countries were selected to ensure a range of geographic locations, as well as varying degrees of progress in workforce development. The UK, for example, has developed a registration system for PHN professionals. Iceland and Sweden have developed graduate degree programmes in PHN. Finland is known for its successful implementation and outcome of PHN interventions ${ }^{(28)}$. Ireland, Slovenia and Spain, however, indicated little prior involvement in PHN workforce development.

A purposeful sampling technique was used to select informants who had sound knowledge of PHN and were prepared to give in-depth information in relation to the research question. Invitations to participate in the study were directed through known academic faculty members and professional networks in each country. Faculty and network members received information on the study and were invited to identify national key stakeholders involved in PHN to extend the consultation sample frame. The selection of participants was made in respect to their known $\mathrm{PHN}$ experience in one of the following sectors: academia, government (ministries and executive national agencies), regional and local authorities (public health offices and primary health-care centres), the food industry, professional organizations and non-governmental organizations (see Table 2). We did not use education as a selection criterion, since nutrition education is a very young academic discipline and not a criterion to work in PHN. The final selection included sixty-five individuals. Five persons declined participation and the total number of informants included was thus sixty.

The Regional Ethics Committee in Stockholm, Sweden approved the study.

\section{Data analysis}

Content analysis focuses on the characteristics of language as communication with attention to the content or contextual meaning of the text ${ }^{(29,30)}$. According to Downe-Wamboldt ${ }^{(31)}$, the goal of content analysis is 'to provide knowledge and understanding of the phenomenon under study' (p. 314). Content analysis may apply an inductive or deductive approach. While the inductive approach moves from the specific to the general, and is often used in theory development, a deductive approach is based on earlier theory or a model and thus moves from the general to the specific $^{(30)}$. In our study, we used more of a deductive approach. When identifying a framework within which the material could be categorized and sorted, we drew upon themes previously identified in the workforce development literature (i.e. the policy environment, public health organizations and workforce composition). Each of these themes was coded to identify constraining and enabling factors.

\section{Methodological considerations}

In qualitative research the concepts of credibility, dependability and transferability have been used to describe the trustworthiness of the research process ${ }^{(32)}$. 'Transferability' refers to the degree to which the findings can be transferred to another context and is discussed further under 'Limitations'. 'Credibility' refers to how well data and analysis address the research focus. The interpretation of a text involves multiple meanings and any interpretation of text will be influenced by the researcher's own personal history and ontology. It is therefore not desirable that only one researcher performs data collection and analysis. In our study, the first and last authors independently coded a sample of texts to compare 


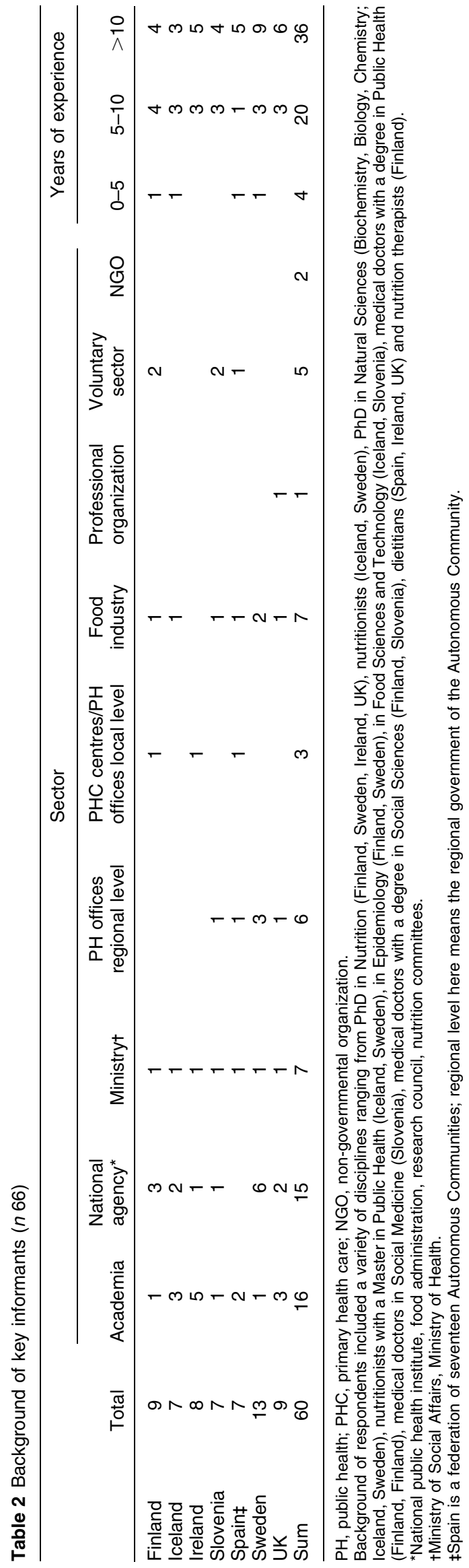

codes and categories. We coded with the assistance of the software program NVivo 8. If differences arose, discussion took place until agreement was reached. A possible limitation might be that that the first author conducted all of the interviews. The use of the same interviewer might have affected the data since gender and age might influence the interview situation ${ }^{(30)}$. However, we made a deliberate choice to have the same person interview all of the informants to enhance consistency during data collection. According to Lincoln and $\mathrm{Guba}^{(32)}$ (p. 299), 'dependability' refers to the degree to which data change over time and alterations are made during the data analysis. To further avoid inconsistency during data collection, the interviews were performed with a semi-structured interview guide. To check for consistency and richness of data, we discussed the data in a forum with senior researchers with knowledge in the subject.

Table 3 summarizes some of the patterns formulated into categories that derived from the analysis. Table 4 summarizes some of the main differences in terms of workforce development between the countries.

\section{Results}

Findings from the analysis are presented under three workforce development areas: (i) policy environment; (ii) public health organizations; and (iii) workforce composition. The findings are drawn from the data in the form of informants' own views and experiences. Quotations have been chosen in order to reflect the key informants' views on each of the three areas.

\section{Policy environment}

Most informants were positive about recent policy developments that placed issues such as nutrition, healthy lifestyles and obesity prevention on the governmental agenda; however, a lack of policies supporting workforce development was also noted. Many participants suggested that developing a PHN workforce was not an issue debated at governmental level or in other high-level forums. Only in the UK was workforce development of public health nutritionists debated and championed by a professional organization.

One informant from the UK, who has been involved in Government commissions related to PHN, said:

The government has been quite active, over the last 15 years. They have had nutrition on the agenda, and there are policy documents ... so within the government policy-making mechanism, the case has been made and the challenge to nutritionists is not to tell the government what the issue is, but how to deliver. (Informant from the UK)

Another theme emerged that reflected a lack of connectivity between policy goals at the national and 
Table 3 Constraining and enabling factors to workforce development

\begin{tabular}{|c|c|c|c|c|}
\hline & \multicolumn{3}{|c|}{ Constraining factors } & Enabling factors \\
\hline & Category & Category content & Category & Category content \\
\hline \multirow[t]{2}{*}{ Policy environment } & Lack of supportive policies & $\begin{array}{l}\text { Lack of policies, laws, regulations that } \\
\text { aim to develop the PHN workforce, } \\
\text { policy ideas focus on a workforce with } \\
\text { general public health skills and } \\
\text { competencies }\end{array}$ & Windows of opportunities & $\begin{array}{l}\text { Policy change and agenda setting relate } \\
\text { to opportunities such as sudden media } \\
\text { interest, changes in the administration, } \\
\text { WHO conferences and publications }\end{array}$ \\
\hline & Lack of connectivity & $\begin{array}{l}\text { Lack of financial support for the } \\
\text { implementation of PHN projects at } \\
\text { regional level, lack of continuity } \\
\text { between policy goals at national and } \\
\text { implementing levels }\end{array}$ & $\begin{array}{l}\text { Leadership role of national public } \\
\text { health agencies and individuals }\end{array}$ & $\begin{array}{l}\text { Leaders have an important role to } \\
\text { advocate the PHN issue, to join others } \\
\text { to build a knowledge network, to } \\
\text { communicate health behaviours to } \\
\text { media and high-rank officials }\end{array}$ \\
\hline \multirow[t]{2}{*}{ Public health organizations } & $\begin{array}{l}\text { Fragmented support for } \\
\text { PHN initiatives }\end{array}$ & $\begin{array}{l}\text { Difficult to get support for PHN services } \\
\text { and projects, PHN practitioners need } \\
\text { to push and promote PHN projects } \\
\text { themselves }\end{array}$ & $\begin{array}{l}\text { Institutional structure with PHN } \\
\text { goals at regional and local level }\end{array}$ & $\begin{array}{l}\text { Regional and local authorities with PHN } \\
\text { goals and objectives }\end{array}$ \\
\hline & $\begin{array}{l}\text { Clinical health-care } \\
\text { perspective }\end{array}$ & $\begin{array}{l}\text { Health authorities and decision makers } \\
\text { have a clinical and medical } \\
\text { perspective, priorities are directed } \\
\text { towards health-care services }\end{array}$ & Voluntary sector & $\begin{array}{l}\text { NGO to carry out PHN interventions and } \\
\text { programmes }\end{array}$ \\
\hline \multirow[t]{3}{*}{ Workforce composition } & Novice character & $\begin{array}{l}\text { Small workforce, unknown workforce, } \\
\text { lack of professional organization, lack } \\
\text { of identity, lack of distinction to other } \\
\text { professional groups }\end{array}$ & Agents of change & $\begin{array}{l}\text { Competent individuals who can } \\
\text { demonstrate change and contribute } \\
\text { to workforce development, individual } \\
\text { motivation the main push for } \\
\text { competency development }\end{array}$ \\
\hline & $\begin{array}{l}\text { Incoherent workforce } \\
\text { composition }\end{array}$ & $\begin{array}{l}\text { Health-care staff dominate, } \\
\text { multidisciplinary, lack of competencies } \\
\text { within the current workforce }\end{array}$ & & \\
\hline & $\begin{array}{l}\text { Lack of workforce } \\
\text { preparation }\end{array}$ & $\begin{array}{l}\text { Lack of formal training, lack of practical } \\
\text { orientation within nutrition } \\
\text { programmes, inconsistency in skills }\end{array}$ & & \\
\hline
\end{tabular}

PHN, public health nutrition; NGO, non-governmental organization. 
Table 4 Differences and similarities between countries in terms of workforce development

\begin{tabular}{|c|c|c|c|c|c|c|c|}
\hline \multirow[b]{2}{*}{ Workforce development category } & \multicolumn{7}{|c|}{ Country } \\
\hline & Finland & Iceland & Ireland & Slovenia & Spain & Sweden & UK \\
\hline Governmental recognition of the PHN workforce & - & - & - & - & - & - & + \\
\hline $\begin{array}{l}\text { Comprehensive public health agency at national level with } \\
\text { expert and leadership role }\end{array}$ & ++ & + & + & + & + & + & + \\
\hline Individuals as leaders in PHN & ++ & + & + & ++ & + & + & + \\
\hline $\begin{array}{l}\text { Institutionalized PHN goals and objectives at regional and } \\
\text { local levels }\end{array}$ & + & + & + & ++ & + & ++ & ++ \\
\hline Voluntary sector makes an important contribution & ++ & + & + & ++ & + & + & + \\
\hline Workforce preparation in terms of PHN training & - & + & + & - & - & + & + \\
\hline Professional organization in $\mathrm{PHN}$ & - & - & - & - & - & - & ++ \\
\hline Title of public health nutritionist used by practitioners & - & - & - & - & - & - & + \\
\hline Workforce with consistent skill base in PHN & - & - & - & - & - & - & - \\
\hline
\end{tabular}

PHN, public health nutrition.

++ , existing; + , fragmented; - , missing.

sub-national implementing levels. The importance of nationally set goals was not necessarily recognized when decisions were made at regional and local levels. This picture was seen in Spain where informants had suggestions for improving the situation:

We had this idea here, you know every city has a small team with a $\mathrm{PH}$ [public health] responsibility, but the problem is that the cities are very far from each other and don't really learn from each other, so we set up a strategy here in the Catalonian government, and the aim is to come nearer to the Catalonian PH system and implementation. We see the need to coordinate these teams and to set up the priorities in the different regions, from where the different teams can work. You know, until now we haven't had an arm in the different regions, we have only proposed policies and recommendation, and the teams in every city have been working quite inefficiently. (Informant from Spain)

Factors that facilitated why and how PHN could become part of the political agenda and gain the attention of decision makers were often attributed to windows of opportunity. Windows of opportunity arose in a variety of ways, including a government ministry taking special interest in nutrition issues, a ministerial meeting provided by the WHO, increased media attention in some countries and changes in the political administration that furthered the PHN agenda. Changes in the Ministry of Health in Slovenia facilitated policy change as shown by the following quotation:

I started being only working with one person, and it was called ministry of health care. And then we started up the public health sector, then we started employing people, not only in public health nutrition but also in public health, and in the end we were twenty people working there. (Informant from Slovenia)

Windows of opportunities were often discussed in relation to leaderships. Both institutions and specific individuals were given as examples of leaders. A good leader was described as someone who has the ability to take advantage of windows of opportunities and advocate for PHN issues. Sound research skills, establishing professional competencies, developing education and training programmes, fostering intersectorial partnerships, network building skills and media communication expertise were also noted as leadership qualities.

Strong institutions were seen to facilitate and foster the development of these attributes. In Finland, the public health institute has a broad mandate, is supported with human and financial resources and functions as an expert agency. Furthermore, the monitoring of health determinants was considered to be an important task to be carried out by leading public health institutes. One informant, with an expert position at national level, explained:

I want to come back to the monitoring, I think it is really important, not to monitor the diseases, but the risk factors and the behaviours, because if you have a good system, which monitors how smoking is developing, how blood pressure is developing, blood cholesterol levels, it is really important, it gives feedback to the people, it gives feedback to the politician. We always say, what is measured, gets talked about. (Informant from Finland)

\section{Public bealth organizations}

A fragmented support for PHN services at the implementation level, both between and within countries, was also identified as a challenge. Practitioners from Ireland, Finland and Spain described how they struggled to get support for PHN projects and programmes. Some public health directors supported PHN services, while others were more reluctant. One practitioner at the local level described her experiences:

... we have been writing to the city council that we need more human resources, but we don't get any support. But in $\mathrm{xxx}$, there it is much easier, and they 
have got much more employments and that depends on the people sitting in the council and their priorities, and also on the directors of the hospital ward, because she is deciding, so it depends on the priorities of the people in decisionmaking positions. My former boss, he was in favour of dietitians or nutrition therapists, and when he was alive, he said that is should be one dietitian on every health centre, and not as it now, one for three health centres. (Informant from Finland)

Another constraining factor was the clinical health perspective among decision makers. One informant from Spain, with a PHN position at national level, shared her view:

In June, we had the first national conference in health promotion and prevention, and I was a member of the panel together with my colleagues in the regions, and I noticed that the panel was very medical orientated. I tried to put in other things, but it was a problem. They don't understand, they think that physical activity and nutrition is a problem for the individuals. (Informant from Spain)

An informant from Ireland, with experience working at community level, explained:

... in the current climate in Ireland ... it's very much on the treatment and that's where the priority is. It is all about waiting lists, all about beds and all about treatment and that's where it is. And there is where the money is going. (Informant from Ireland)

An enabling factor for some participants was that PHN service delivery has gradually become more institutionalized over the years. Practitioners from the UK and Sweden described that PHN had become part of the regional and local policy goals and that facilitated their work. This was also noted by interviewees from Slovenia, where regional public health institutes carry out many of the PHN projects in parallel with a WHO-initiated Country Integrated Non-Communicable Diseases Intervention Programme (CINDI). In Finland, the voluntary sector, with non-governmental organizations such as the Finnish Folkhälsan, was an important body in providing preventive health-related services.

\section{Workforce composition}

An important constraint was the novice, or early developmental stage, of the workforce. A workforce with special training in PHN was found only in the UK, Iceland and Sweden and was described as being very small in all three. The novice character of the workforce has made the work itself inconsistent due to differences in skill bases. However, in the UK the title public health nutritionist' was used by practitioners and there was a professional organization to support them. One informant from the UK, who has a registration as a public health nutritionist, described the situation:

I think there are a lot of people who are registered as public health nutritionists, and if we look at them, and I have met some and I know that they ... we don't function in the same way, we don't have the same evidence base to practice, we don't have the same skills. I have seen it in first hand so to say, there are too much variation, even if your job only require you to use certain part of your skill base, it is good to have a consistent skill base. (Informant from the UK)

Another common concern expressed was the lack of clear distinctions with regard to other professional categories, such as dietetics.

The lack of cohesion of the current workforce was also identified as a constraint. Informants from all countries pointed out that the largest part of the PHN services was carried out by a workforce with no special training in nutrition. The current workforce included a wide variety of professionals, such as general practitioners, nurses, midwives, food technologists, teachers, public health trainers, food educators and meal planners. Even if informants acknowledged that these professionals are important in terms of reaching the whole population, the problem was that many of them lacked the necessary formal education and training. One informant from Slovenia, who graduated in PHN abroad, explained:

Our professionals are actually not primary professions in public health nutrition. They have some courses in nutrition, so there are some competencies in this, but not enough, not certified or official ones. (Informant from Slovenia)

A participant from Spain, working at national level to support policy development, commented:

No, I think in Spain and this is characteristics of public health in this moment; everybody can do a role in this area. They don't ask for a special training to work in public health. Really, really anybody can work in this field. (Informant from Spain)

A major constraining factor discussed by informants from Slovenia and Spain was the lack of training to work in the field of PHN. Most training was directed to clinical settings. Only in Iceland did informants mention training as an enabling factor. In Sweden and the UK informants mentioned that current training in nutrition and PHN provided good research skills, but needed further practical orientation. In Ireland and Finland, PHN training was emerging.

An enabling factor discussed in all of the countries related to the individuals themselves acting as important agents of change. Using their expertise, the informants managed to change practice and promote the PHN workforce. 
One informant, who works to promote well-being and healthy lifestyles in the larger community, suggested:

Because once people see it in action, they value it. That's what happened to me, being in the team, showing what a nutritionist can bring made them create a public health nutritionist post. (Informant from the UK)

Another informant described her career path from a nutritionist to a public health specialist like this:

You know it is kind of building up experiences and competencies really ... I was a nutritionist at that time. And then I diversified and used those skills I gained through different stakeholders and settings and applied it to looking at how we could improve community health programmes. I registered as a public health specialist, and I completed a master in public health. I then moved into national government and became responsible for community health and moved across to become responsible for policies and community strategies. (Informant from the UK)

\section{Discussion}

These findings show that there are similarities and differences in the constraining and enabling factors for PHN workforce development among the countries studied. The main constraining factors for most countries relate to the lack of a supportive policy environment, a fragmented PHN organizational structure and lack of a cohesive workforce to achieve PHN objectives. Enabling factors were identified as the presence of skilled and persistent individuals acting as leaders and agents of change.

All informants with the exception of those from the UK identified a lack of a supportive policy environment for workforce development of public health nutritionists. In the UK, the Nutrition Society has been active in promoting and debating the role of a public health nutritionist. In Spain, there was a lack of connectivity between policy goals formed at national and sub-national implementing levels. Although it is the responsibility of each public health organization at regional and local level to identify which national policy objectives they wish to contribute to, it is important that there is connectivity and coordination between broader political public health goals and sub-level organizational aims and activities ${ }^{(17,19,33)}$. Our study suggests that communication and coordination between national policy makers and local implementers is a key factor in achieving policy objectives and strengthening service delivery.

At the implementation level, major constraints were identified as the clinical orientation of health authorities in Spain and Ireland and the fragmented support for PHN initiatives in Ireland, Finland and Spain. The findings show that in some regions there were supportive managers and PHN initiatives going on, while in others the activities were more sporadic and priorities were directed to clinical care. Our study, like others, suggests that a contributing factor to the fragmentation of PHN infrastructure ${ }^{(21,34)}$ is the lack of defined and integrated standards and objectives related to PHN within organizations. The study confirms that defining PHN objectives at the organizational level facilitates workforce development ${ }^{(35,36)}$. In Slovenia, Sweden and the UK, policy goals related to PHN were part of the institutional public health structure at the regional/local level and enabled the delivery of PHN services and programmes.

Establishing core PHN functions can enable organizations to contribute to promoting, protecting or maintaining the nutrition-related health of the population. Furthermore, documentation of core functions helps organizations to understand the human resource roles and skills that they need to develop in order to be able to contribute to this effort. This kind of information can be put together to define which areas need further competency development, staff and technical support.

At the individual practitioner level, a major constraint identified in all countries was the lack of cohesion among the current workforce. The informants from all countries pointed to the fact that the largest part of PHN activities is carried out by professional groups other than nutritionists (e.g. general practitioners, nurses, midwives, food technologists, teachers and public health trainers), who generally have limited training in nutrition. In the UK, where there is a relatively newly formed workforce with training in PHN, the lack of clear distinction and boundaries between PHN and other professions such as dietetics was noted.

The lack of professional identity of public health nutritionists has been highlighted in other studies ${ }^{(24,37)}$. A contributing factor may be inadequate preparation of the current workforce. Nutrition and public health training is limited and even in countries where there are PHN programmes, training is not seen to provide adequate practical skill development. There is therefore discussion of the need to regulate training in $\mathrm{PHN}^{(38)}$.

The role of training is also important in building professional identity ${ }^{(39)}$. Palermo and McCall report that mentoring or on-the-job training, rather than formal training, can be an effective strategy for building a professional identity and development of necessary competence $^{(40)}$, especially among a novice workforce. Our findings support the suggestion of others that workforce development must be the result of partnerships between current workforce groups, public health organizations and training institutions ${ }^{(41)}$.

Lastly, the analysis highlights the importance of leaderships as an important driver for fostering intersectorial partnerships, advocating for policy change, establishing professional competencies and developing education and training programmes. 
The influence of expert networks, policy entrepreneurs and agents of change has been examined in policy diffusion and agenda-setting studies ${ }^{(42-48)}$. In his diffusion theory of innovations, Rogers describes opinion leaders and technically skilled agents of change as important factors in the diffusion of innovation and new practices $^{(49)}$. Considering the emerging nature of PHN, it is likely that leaders and agents of change have already been driving development. A more detailed examination however of who is involved in PHN policy, what specific kinds of issues are addressed and to what extent policy change has occurred, would help to inform further PHN workforce policy and development.

\section{Limitations}

Since we have focused less on the historical, political, institutional, social and cultural contexts that shape the findings, other researchers in the same area might find it difficult to transfer and contrast the present findings to their setting. On the other hand, we have inserted quotations to facilitate the reader's decision as to whether or not the findings are transferable to another context. Also we are aware of the importance of comparing interpretation with literature in this field.

\section{Conclusion}

The present study explored public health nutritionists' perceptions of workforce development. Although the study was conducted in seven countries and may not be generalized to others, the findings suggest the need to strengthen coordination between policy and implementation levels. Organizations are advised to further define aims and objectives relevant to PHN. Leaders and agents of change will play important roles in fostering intersectorial partnerships, advocating for policy change, establishing professional competencies and developing education and training programmes.

\section{Acknowledgements}

This study was supported by the Directorate General for Education and Culture of the European Commission and its Lifelong Learning Programme (Leonardo da Vinci) called JobNut. There are no conflicts of interest. S.K. took a lead role in study design, data collection, analysis, drafting and editing the manuscript. A.Y. contributed to the study design, drafting and final editing of the manuscript. K.J. contributed to the drafting and final editing of the manuscript. E.F. gave methodological support and contributed to the final editing of the manuscript. A.F., I.T. and S.J. contributed to the design and implementation of the study and took part in the final editing of the manuscript. The authors are greatly thankful to the respondents in Finland, Iceland, Ireland, Slovakia, Slovenia, Spain, Sweden and the UK.

\section{References}

1. Steyn NP, Mann J, Bennett PH et al. (2004) Diet, nutrition and the prevention of type 2 diabetes. Public Health Nutr 7, 147-165.

2. Swinburn BA, Caterson I, Seidell JC et al. (2004) Diet, nutrition and the prevention of excess weight gain and obesity. Public Health Nutr 7, 123-146.

3. Trübswasser U \& Branca F (2009) Nutrition policy is taking shape in Europe. Public Health Nutr 12, 295-306.

4. Hughes R (2008) Workforce development: challenges for practice, professionalization and progress. Public Health Nutr 11, 765-767.

5. Lichtveld M, Cioffi JP, Baker E et al. (2001) Partnership for frontline-success: a call for national action agenda on workforce development. J Public Health Manag Pract 7, 1-7.

6. Serra-Majem L (2009) Moving forward in public health nutrition - the I World Congress of Public Health Nutrition Introduction. Nutr Rev 67, Suppl. 1, S2-S6.

7. Hughes R (2007) Introduction to public health nutrition practice. In Public Health Nutrition: From Principles to Practice, pp. 265-271 [M Lawrence and A Worsley, editors]. Crows Nest, NSW: Allen \& Unwin.

8. Lawrence MA, Galal O, Margetts BM et al. (2009) Building global alliances for public health nutrition training. Nutr Rev 67, Suppl. 1, S66-S68.

9. Landman J, Buttriss J \& Margetts B (1998) Curriculum design for professional development in public health nutrition in Britain. Public Health Nutr 1, 69-74.

10. Cena H, Roggi C, Lucchin L et al. (2010) Health nutrition practice in Italy. Nutr Rev 68, 556-563.

11. Hughes R (2004) Competencies for effective public health nutrition practice: a developing consensus. Public Health Nutr 7, 683-691.

12. Torheim LE, Granli GI, Barikmo I et al. (2009) A survey among potential employers for developing a curriculum in public health nutrition. Public Health Nutr 12, 1039-1045.

13. Yngve A, Thulin S, Kennedy N et al. (2007) Training in public health nutrition in Europe results from the EUNUTNET project. Ann Nutr Metab 51, 334-335.

14. Yngve A, Warm D, Landman J et al. (2001) A European Master's Programme in Public Health Nutrition. Public Health Nutr 4, 1389-1391.

15. Baillie E, Bjarnholt C, Gruber M et al. (2009) A capacitybuilding conceptual framework for public health nutrition practice. Public Health Nutr 12, 1031-1038.

16. Hughes R (2006) A socioecological analysis of the determinants of national public health nutrition work force capacity: Australia as a case study. Fam Community Health 29, 55-67.

17. Lichtveld MY \& Cioffi JP (2003) Public health workforce development: progress, challenges, and opportunities. J Public Health Manag Pract 9, 443-450.

18. Miner KR, Childers WK, Alperin M et al. (2005) The MACH model: from competencies to instruction and performance of the public health workforce. Public Health Rep 120, 9-15.

19. Potter MA, Barron G \& Cioffi JP (2003) A model for public health workforce development using the National Public Health Performance Standards Program. J Public Health Manag Pract 9, 199-207.

20. Staron M (2009) Workforce development - a whole-ofsystem model for workforce development. In Public Health Workforce Developments Literature Scan, Review \& Literature [IL Bourgeault, C Demers and S Donovan, editors]. http://www.peelregion.ca/health/resources/pdf/ Ivy-Bourgeault-Workforce Development.pdf (accessed December 2011).

21. Haughton B \& George A (2008) The Public Health Nutrition workforce and its future challenges: the US experience. Public Health Nutr 11, 782-791. 
22. Haughton B \& Shaw J (1992) Functional roles of today's public health nutritionists. J Am Diet Assoc 92, 1218-1222.

23. Haughton B, Story M \& Keir B (1998) Profile of public health nutrition personnel: challenges for population/ system-focused roles and state-level monitoring. J Am Diet Assoc 98, 664-670.

24. Fox A, Chenhall C, Traynor M et al. (2008) Public health nutrition practice in Canada: a situational assessment. Public Health Nutr 11, 773-781.

25. Jonsdottir S, Hughes R, Thorsdottir I et al. (2011) Consensus on the competencies required for public health nutrition workforce development in Europe - the JobNut project. Public Health Nutr 14, 1439-1449.

26. Huberman M \& Miles MB (editors) (2002) The Qualitative Researcher's Companion. London: SAGE Publications.

27. Hall PA (1993) Policy paradigms, social learning, and the state: the case of economic policymaking in Britain. Comp Polit 25, 275-296.

28. Pietinen P, Lahti-Koski M, Vartiainen E et al. (2001) Nutrition and cardiovascular disease in Finland since the early 1970s: a success story. J Nutr Health Aging 5, 150-154.

29. Tesch R (1990) Research Design: Qualitative and Quantative Approaches. London: SAGE Publications.

30. Krippendorff K (2004) Content Analysis - An Introduction to its Methodology. London: SAGE Publications.

31. Downe-Wamboldt B (1992) Content analysis: method, applications, and issues. Health Care Women Int 13, 313-321.

32. Lincoln Y \& Guba E (1985) Naturalistic Inquiry. Newbury Park, CA: SAGE Publications.

33. Kennedy VC \& Moore FI (2001) A systems approach to public health workforce development. J Public Health Manag Pract 7, 17-22.

34. Kondro W (2008) Canada needs paradigm shift in public health nutrition. Can Med Assoc J 179, 1259-1260.

35. Hughes R (2003) Public health nutrition workforce composition, core functions, competencies and capacity: perspectives of advanced-level practitioners in Australia. Public Health Nutr 6, 607-613.

36. Palermo C, Hughes R \& McCall L (2010) An evaluation of a public health nutrition workforce development intervention for the nutrition and dietetics workforce J Hum Nutr Diet 23, 244-253.

37. Steyn NP \& Mbhenyane XG (2008) Workforce development in South Africa with a focus on public health nutrition. Public Health Nutr 11, 792-800.

38. Margetts B (2006) Nutrition, public health, and the new nutrition science: academic thought, professional action. Public Health Nutr 9, 407-410.

39. Freidson E (1988) Professional Powers: A Study of the Institutionalization of Formal Knowledge. Chicago, IL: The University of Chicago.

40. Palermo C \& McCall L (2008) The role of mentoring in public health nutrition workforce development. Perspectives of advanced-level practitioners. Public Health Nutr 11, 801-806.

41. Bourgeault IL, Demers C \& Donovan S (editors) (2009) Public Health Workforce Development Models Literature, Scan, Review \& Synthesis. http://www.peelregion.ca/ health/resources/pdf/Ivy-Bourgeault-Workforce Development. pdf (accessed December 2011).

42. Dolowitz D \& Marsh D (1996) Who learns what from whom: a review of the policy transfer studies. Polit Stud XIIV, 343-357.

43. Drezner DW (2005) Globalization, harmonization, and competition: the different pathways to policy convergence. J Eur Public Policy 12, 841-859.

44. Evans M \& Davies J (1999) Understanding policy transfer: a multi-level, multi-disciplinary perspective. Public Adm 77, 361-385.

45. Holzinger K \& Knill C (2005) Causes and conditions of cross-national policy convergence. J Eur Public Policy 12, 775-796.

46. Jönsson K (2002) Translating foreign ideas into domestic practices: pharmaceutical policies in Laos and Vietnam. Doctoral dissertation, Lund University.

47. Knill C (2005) Introduction: cross-national policy convergence: concepts, approaches and explanatory factors. $J$ Eur Public Policy 12, 764-774.

48. Levi-faur D (2005) 'Agents of knowledge' and the convergence on a 'new world order': a review article. J Eur Public Policy 12, 954-965.

49. Rogers EM (1995) Diffusion of Innovations, 4th ed. New York: The Free Press. 